\title{
The Joint Influence of Albedo and Insulation on Roof Performance: A
}

\section{Abstract}

13 The advanced Princeton Roof Model (PROM) is evaluated and then applied to quantify

14 the heat transferred through various modular roof structures over an entire year. The goal

15 is to identify an optimal combination of roof reflectivity and insulation thickness that will

16 reduce energy consumption and minimize cost. Meteorological data gathered over the

17 Northeastern United States (Princeton, NJ) is used to force PROM. Our results reveal that

18 for new constructions or for retrofits in the region, an R8.4 (around $46 \mathrm{~cm}$ thick roof

19 insulation) white roof (assumed albedo $=0.6$ or greater) would significantly reduce the

20 combined heating and cooling load attributable to the roofs. The wintertime penalty of

21 white roofs is also shown to be insignificant compared to their summertime benefits. The

22 findings are pertinent to many other densely populated areas with comparable climates

23 where, despite a much higher number of heating versus cooling degree-days, white roofs

24 are overall advantageous. A cost optimization analysis found that doubling, tripling and

25 quadrupling the insulation thickness from the baseline case of $5.08 \mathrm{~cm}(2 \mathrm{in})$, at an albedo

26 of 0.45 , requires 13,17 and 19 years, respectively, to recover the additional cost incurred. 


\section{Keywords}

28 Cool Roof, Roof energy savings, Roof Albedo, Roof Heat Flux, Roof Insulation,

29 Princeton Roof Model

\section{$31 \quad 1$ Introduction}

32 This modeling study is focused on understanding the role played by roof albedo and

33 insulation in modulating the heat transfer through roofs, and on quantifying the resulting

34 impact on building energy consumption. The overall goal is to provide guidance on roof

35 design that would help reduce the large environmental footprint of building air

36 conditioning: in the US, about $20 \%$ of primary energy is consumed in heating and

37 cooling of buildings; this (heating and cooling of US buildings only) is equivalent to

38 about $3.5 \%$ of the worldwide consumption of primary energy [1].

39 One of our unambiguous conclusions from an associated experimental study [2] was that

40 white roofs were highly effective in reducing the cooling loads during the summer

41 months, while insulation thickness (R-value) was the main determinant of roof energy

42 efficiency during winter periods. But the observational study was not well suited for

43 exploring the optimum (in term of financial cost) combination of albedo and R-value for

44 a given geographical location. Our further investigations detailed in this article will use

45 the Princeton Roof Model (PROM), which is a component of the broader Princeton

46 Urban Canopy Model (PUCM, [3]) and which can capture the vertical heterogeneity of

47 complex modern roofing structures, to address this fundamental question. The model will

48 be applied to simulate the transfer of heat in/out of multiple modular roofs of varying

49 membrane reflectivity and thickness, continuously for an entire year, using 
50 hydrometeorological forcing data collected in Princeton, NJ, in the US Northeast. The

51 aim is to identify the optimal combination of albedo and insulation that would minimize

52 total cost (material and operating energy costs) for roofs in the region, but the research

53 methodologies used here (though clearly not the conclusions) can obviously be applied to

54 any other site anywhere in the world. The observational part of the study [2], as well as

55 previous research in the same region [4], suggest that the albedo expected to yield the

56 highest energy efficiency would be a high one, corresponding to a white roof. The

57 simulations we conduct here will aid in corroborating these conclusions, and the

58 expansion of the parameter space (albedo and insulation) will allow us to explore/identify

59 the optimal roof design.

60 Research in the last two decades has highlighted the importance of roofs as a possible

61 tool to mitigate urban heat islands and improve energy sustainability [5-7]. A number of

62 numerical studies have been conducted to assess and quantify the effectiveness of green

63 roofs and white roofs in moderating the urban microclimate and improving energy

64 efficiency of building structures. Akbari et al. [8] used DOE 2 to simulate energy

65 consumption for typical buildings at 11 Metropolitan areas and quantified the

66 corresponding energy savings. The DOE 2 model has been extensively used in the

67 literature to study the effectiveness of highly reflective roofs [9]. Sailor et al. [10] further

68 improved the DOE 2 model by adding a green roof module. DOE 2 is primarily used as a

69 numerical engine for several building energy simulation programs like eQUEST [11] and

70 EnergyPlus [12]. Other notable models include the DeST, predominantly used in China

71 and Energy Express developed by CSIRO, Australia [11,13]. In addition to the stand-

72 alone building energy simulations models, urban canopy models (UCM) have also been 
73 used to study the energetic interactions between the building envelope and the

74 environment [14]. UCMs represent the street canyon as an infinite rectangular cavity

75 bordered by two buildings (usually of equal height in the single layer representation; an

76 infinite regular array of cubes can also be represented with minor modifications to the

77 model)[15]. These models are widely used by urban climatologists as they can be readily

78 coupled to mesoscale climate models. In this study we use the Princeton Roof Model

79 (PROM) to simulate the energy transfer through the roof between the building interior

80 and the exterior. PROM is part of the broader Princeton Urban Canopy Model and is

81 explained in detail in the succeeding section.

82

832 Methods

\section{$84 \quad 2.1$ Princeton Roof Model}

85 A schematic of PROM is shown in figure 1. A primary advantage in using PROM is its

86 ability to account for the various distinct layers in a roof. Many current models consider

87 roofs to be vertically homogenous, and assume steady state conditions when solving for

88 the heat flux [16]. These assumptions might be acceptable for simple, relatively thin older

89 roof designs. However, for the modern multilayer roofs, accounting for the various

90 vertical layers, and for the transient dynamics of the heat flux (since the conduction time

91 scale through these roofs can be $\sim 24$ hours), becomes important. In contrast to these

92 models, PROM accounts for the thermal dynamics in individual roofing elements/layers

93 to compute the heat transferred between them. PROM is equipped with a multilayer,

94 spatially-analytical and temporally numerical, conductive heat transfer scheme based on

95 the Green's function solution of the one dimensional heat equation in each layer. 
96 Individual layers of the roofing structure are assigned their distinct physical and thermal

97 properties. Additionally, this analytical scheme obviates the need to spatially discretize

98 the domain, which reduces numerical errors [17]. While this approach is comparable to

99 the relaxed conduction heat transfer equations used in the advanced module of DOE2.1

100 [18], PROM can be applied to any roofing configuration without the need to compute

101 pre-configured roof parameters, as required in DOE2.1. In addition, the time steps in

102 PROM are variable compared to the fixed 1-hr period for DOE2.1 (those fixed time steps

103 are linked to the pre-configured parameters DOE2.1 needs). PROM can also be used to

104 model energy exchanges over vegetated roofs. The implementation and validation of

105 PROM over green roofs is detailed by Sun et al. [19, 20]; these references also provide

106 full further details about the approach used in PROM for solving the heat equation.

107

108

109

110

111

112

113 PROM is one component of the broader Princeton Urban Canopy Model (PUCM), which
114 employs the widely-adopted single layer framework [21] to represent energy exchanges

113 PROM is one component of the broader Princeton Urban Canopy Model (PUCM), which
114 employs the widely-adopted single layer framework [21] to represent energy exchanges

Figure 1 Schematic of Princeton ROof Model (PROM) - Princeton Urban Canyon Model (PUCM) framework. In the schematic of PROM on the left, heat fluxes are denoted with red arrows, along with notations: $H$ for sensible heat flux, $L E$ for latent heat flux, $G$ for heat flux through roof. Figure reproduced from Sun et al. [19].
Princeton UCM

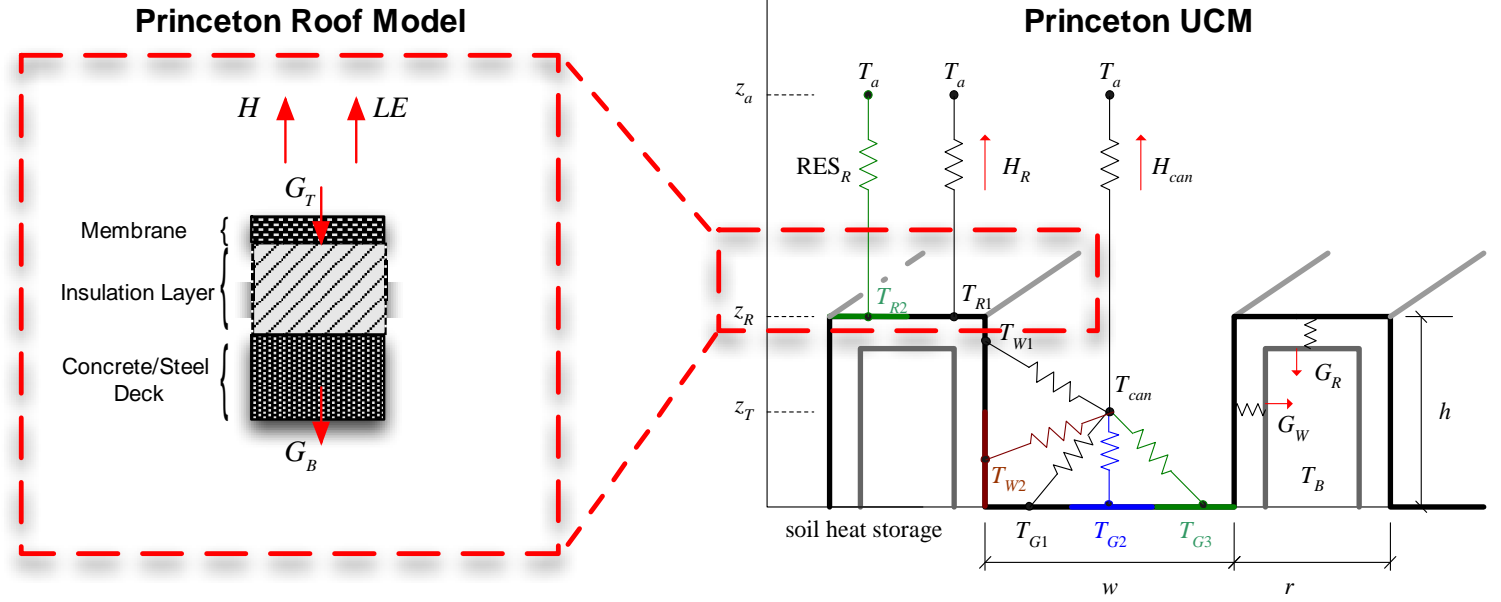


115 over an urban area (though the other aspects of PUCM are irrelevant here). This

116 integration effectively couples the roof structure to the shifting meteorological conditions

117 of the surrounding environment. As such, validations of PUCM [3], [22], [15], and [23]

118 also imply that the convective turbulent heat transfer parameterizations of PROM are

119 reasonably accurate; however, further evaluations are conducted through this study to

120 ensure the model is able to capture the heat transfer dynamics of the roofs under

121 investigation.

122 In the succeeding sections of this article, the integrated, multilayer, spatially-analytical

123 scheme implemented in PROM framework will be evaluated over different roofing

124 structures. The model will then be used to simulate energy exchanges over a suite of

125 roofs with gradually varying albedo and roof thickness, forced by atmospheric data

126 obtained over the validation site in Princeton, NJ. The results from this simulation will

127 then be used to identify the optimal combination of surface reflectivity and insulation

128 thickness to minimize heating and cooling costs over a whole year.

\section{$130 \quad 2.2$ Model Evaluation}

131 Before using PROM to identify the optimal albedo and roof thickness, the model is

132 validated using the extensive and unique heat flux measurements collected at the

133 Princeton Plasma Physics Lab (PPPL) rooftops located in Princeton, New Jersey

$134\left(\mathrm{~N} 40.3489^{\circ} \mathrm{W} 74.6029^{\circ}\right)$. According to the Koppen index [24], the region experiences a

135 continental humid climate. Heat flux and temperature measurements were made at five

136 different rooftops, each with varying albedo, roof thickness and insulation materials.

137 Figure 2 shows the plan view of the installation site. We will denote the roofs as ADMw- 
138 R8.4, THYb-R3.6, LSBb-R4.2, LSBw-R4.2, EGRb-R6.3, where the first three upper case

139 letters indicate the building, the $4^{\text {th }}$ lower case letter indicate whether the roof is white

140 (w) or black (b) and the two digits after the $\mathrm{R}$ indicate the $\mathrm{R}$ value (insulation) of the roof.

141 The SI unit of $R$ is $\mathrm{m}^{2} \mathrm{~K} \mathrm{~W}^{-1}$, and the equivalent US unit is $\mathrm{hr} \mathrm{ft}^{\circ}{ }^{\circ} \mathrm{FBTU}^{-1}$. At each of the

142 five roofs, the heat fluxes were monitored beneath the Ethylene Propylene Diene

143 Monomer (EPDM) membrane and at the bottom of the final insulation layer, i.e at the

144 interface between the insulation foam and roof frame. The complete details of the

145 measurements and schematics of the installed sensors are provided in Ramamurthy et. al.

$146[2]$.

147 Apart from quantifying the thermal state of the roof, the measurements also included

148 ambient weather conditions. The incoming and outgoing shortwave radiation were

149 measured by Davis shortband radiometer (model 6450, accuracy $\pm 90 \mathrm{~W} \mathrm{~m}^{-2}$, resolution

$1501 \mathrm{~W} \mathrm{~m}^{-2}$ ). The surface temperature over different membranes was measured by ZyTemp

151 infrared gun (TNOam, accuracy $0.6{ }^{\circ} \mathrm{C}$ for most of our measurement range, resolution

$1520.0625^{\circ} \mathrm{C}$ ). The Vaisala WXT520 was employed to monitor the ambient atmospheric

153 pressure (accuracy $\pm 1 \mathrm{hPA}$ ), relative humidity (accuracy $\pm 3 \%$ ), wind speed (accuracy \pm

$1543 \%$ at $10 \mathrm{~m} \mathrm{~s}^{-1}$ ), temperature (accuracy $\pm 0.3^{\circ} \mathrm{C}$ ), and precipitation (accuracy $\pm 5 \%$ of

155 measurement). The weather data were logged using a GPRS-based Sensorscope mobile

156 weather network [25]. 


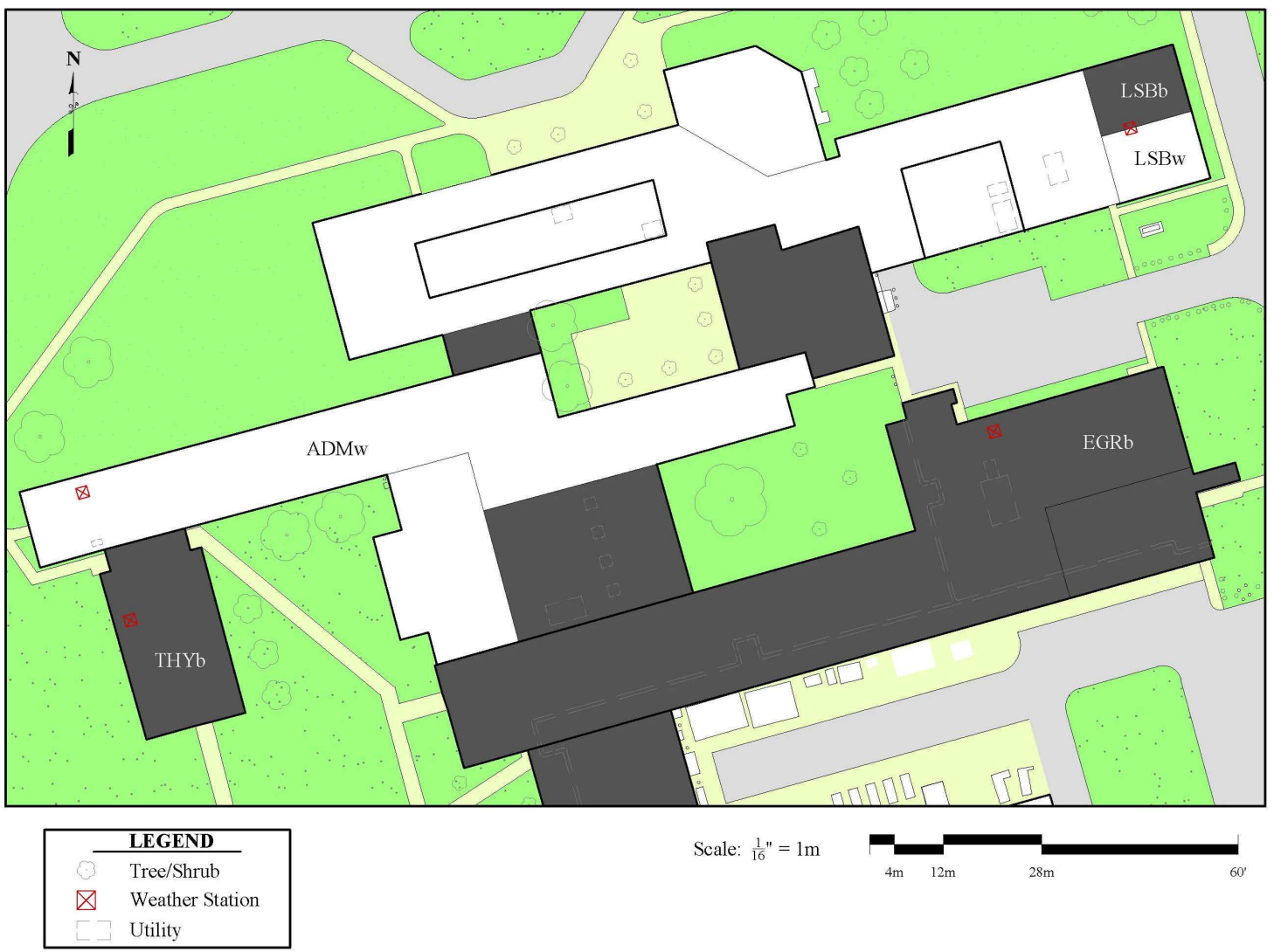

158 Figure 2: Map illustrating the buildings and roof installation at the PPPL test site. The

159 weather stations (red markers) were placed in close proximity to the heat flux sensors and 160 thermocouples installed inside the roof layers. Figure reproduced from Ramamurthy et al. 161 [2].

163 While all roof structures used Polyisocyanurate (PolyIso) foam as the primary insulation 164 material, over the LSBb-R4.2, LSBw-R4.2 and EGRb-R6.3 roofs, a gypsum based

165 fiberglass and plywood were also used as the topmost insulation layer, directly beneath

166 the membrane. All five test roofs were shielded with an EPDM membrane; however, the

167 membrane albedo varied between the rooftops quite considerably. These albedos were

168 independently measured using a combination of downward and upward facing shortband

169 radiometers. The different roofs also varied in age; the LSBw-R4.2 and LSBb-R4.2 were

170 newly installed before the experiment (in the summer of 2012), the ADMw-R8.4 and 
171 THYb-R3.7 were installed in 2005 and 2002 respectively. The EGRb-R6.3 roof was

172 installed in 2009.

173 The measurement accuracy of the thermal state of the roof structures and of the ambient

174 weather conditions are adequate for the analyses conducted here; however, the largest

175 uncertainty in the inputs provided to PROM is in the imposed thermal properties (thermal

176 conductivity and volumetric heat capacity) of the membranes and the insulation

177 materials. While most manufacturers do disclose the lab-tested values, these numbers

178 vary depending on the batches and installation technique; more importantly, they vary

179 considerably with ageing and weathering of the roof. The PolyIso foams, whose cell

180 structures are initially filled with an inert gas that over time gets replaced by air, start

181 experiencing an increase in thermal conductivity [26, 27]. While these changes are hard

182 to estimate and beyond the scope of this experiment, we modeled them by starting with

183 the common values used in the literature and then calibrating them over successive

184 validation runs to match observations. In addition, white membranes are known to start

185 absorbing more radiation due to dirt accumulation over time [28, 29], which reduces their

186 albedo. To capture this variation, the actual albedo was measured and used here. Table 1

187 lists the thermal conductivity and the volumetric heat capacity of all the roofing members

188 as determined through this calibration and used to parameterize the model. The

189 calibration might be biased since it inherently lumps all experimental or modeling errors

190 and determines values for these properties that partially offset these errors, but the

191 validation we show next is able to replicate observed fluxes reasonably well. Therefore,

192 and despite the possibility of some local error cancelations, PROM will be able to 
193 simulate the heat transfer dynamics in roofs with sufficient accuracy to allow us to

194 confidently interpret and build upon its output.

196 Table 1: Heat capacity, thermal conductivity and albedo values used to validate the 197 PROM for various roofs

\begin{tabular}{|c|c|c|c|}
\hline Roof Structure & $\begin{array}{c}\text { Volumetric Heat } \\
\text { Capacity } \\
\left(\mathrm{JK}^{-1} \mathrm{~m}^{-3}\right)\end{array}$ & $\begin{array}{c}\text { Thermal } \\
\text { Conductivity } \\
\left(\mathrm{Wm}^{-1} \mathrm{~K}^{-1}\right)\end{array}$ & Albedo \\
\hline $\begin{array}{c}\text { EGRb-R6.3 } \\
\text { [EPDM, Plywood, PolyIso] }\end{array}$ & $10^{6} \times[1.74,0.9,0.04]$ & {$[0.5,0.1,0.035]$} & 0.06 \\
\hline $\begin{array}{c}\text { THYb-R3.7 } \\
\text { [EPDM, PolyIso] }\end{array}$ & $10^{6} \times[1.74,0.07]$ & {$[0.3,0.009]$} & 0.1 \\
\hline $\begin{array}{c}\text { ADMw-R8.4 } \\
\text { [EPDM, PolyIso] }\end{array}$ & $10^{6} \times[1.74,0.16]$ & {$[0.3,0.015]$} & 0.35 \\
\hline $\begin{array}{c}\text { LSBb-R4.2 } \\
\text { [EPDM, Densdeck, PolyIso] }\end{array}$ & $10^{6} \times[1.74,0.57,0.1]$ & {$[0.4,0.3,0.02]$} & 0.07 \\
\hline $\begin{array}{c}\text { LSBw-R4.2 } \\
\text { [EPDM, Densdeck, PolyIso] }\end{array}$ & $10^{6} \times[1.74,0.57,0.1]$ & {$[0.27,0.3,0.02]$} & 0.65 \\
\hline
\end{tabular}

199 The model was validated for a 3-day period in September 2012 (shown in figure 3 and 4).

200 The forcing data required to run the model was obtained from the meteorological

201 observations over PPPL presented above. Figure 3 compares the model runs indicated by

202 continuous curves to observed heat flux plate data indicated by markers. Overall, given

203 the heterogeneity in albedo, insulation thickness, and construction materials properties, as

204 well as the uncertainty and variability in the hydrometeorological forcing and the fact that

205 partial roof shading is not accounted for in the solar radiation inputs which are taken from

206 an unshaded measurement site, the model performs remarkably well in capturing the heat

207 entering and leaving the top and bottom of the roof interfaces. The model is especially

208 successful in capturing the bottom heat fluxes, at all the sites, indicating that part of the

209 errors near the top are due to the hydrometeorological variability that are not fully 
210 captured in the inputs to the model. PROM is also able to replicate the diurnal variation

211 of fluxes very well. In fact the model only misses the intermittent sharp peaks during the

212 midday period, which could be directly attributed to the averaged input forcing data used

213 to run the model. The model was forced with 30 minute averaged dataset, and it outputted

214 data at 5-minute intervals, which were then averaged over 30 minutes (the actual time

215 step of the model was 5-minute).

216 Table 2 provides the Root Mean Square Error (RMSE), Mean Bias Error (MBE), and the

217 corresponding Percentage RMSE and Percentage Bias (PBIAS) between the observed and

218 modeled data for all five rooftops. In addition, the table also lists Nash-Sutcliffe

219 Efficiency (NSE) of the model. The equations used to calculate these error parameters are:

$$
M B E=\frac{1}{N} \sum_{i=1}^{n}\left(O_{i}-M_{i}\right)
$$

$$
\text { PBIAS }=\frac{\sum_{i=1}^{n}\left(O_{i}-M_{i}\right)}{\sum_{i=1}^{n} O_{i}},
$$

$$
R M S E=\sqrt{\frac{1}{N} \sum_{i=1}^{n}\left(O_{i}-M_{i}\right)^{2}},
$$

$$
\begin{gathered}
\text { PRMSE }=\frac{R M S E}{\frac{1}{N} \sum_{i=1}^{n} O i}, \\
N S E=\frac{\sum_{i=1}^{n}\left(O_{i}-\bar{O}\right)^{2}-\sum_{i=1}^{n}\left(M_{i}-O_{i}\right)^{2}}{\sum_{i=1}^{n}\left(O_{i}-\bar{O}\right)^{2}} .
\end{gathered}
$$

225 In the above set of equations, $O_{i}$ and $M_{i}$ respectively represent the observed and modeled

226 values; $\bar{O}$ is the mean of the observed values; and $N$ is the number of samples. 

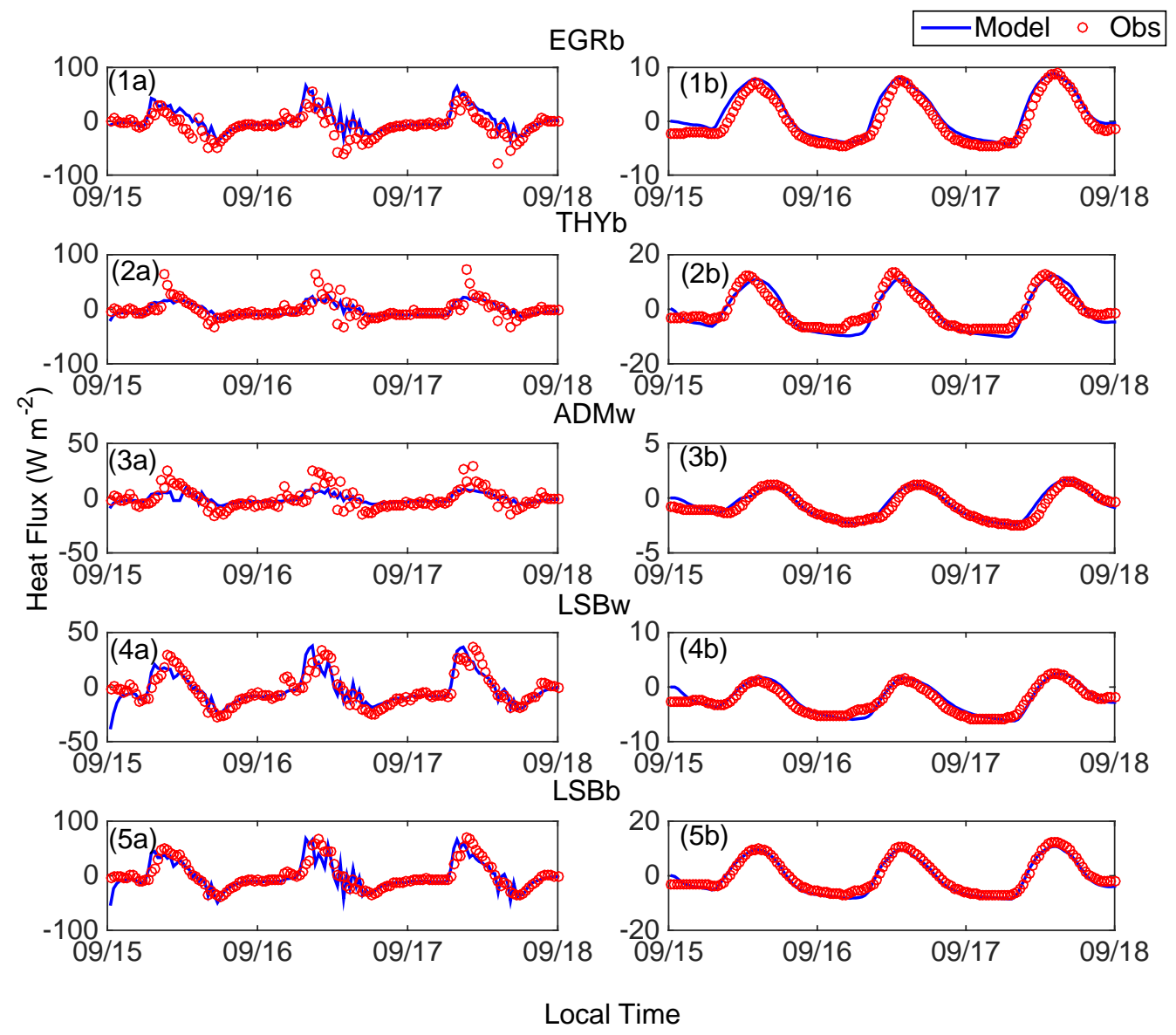

228 Figure 3: Comparing observed heat flux plate measurements made at the top and bottom 229 of various roofs to modeled values (30 minute averages). The left column, 1a, 2a, 3a, 4a 230 and 5a represent heat fluxes at the interface of EPDM membrane and the insulation layer 231 at the top of the roof structure and the right column, $1 b, 2 b, 3 b, 4 b$ and $5 b$, represent the 232 heat fluxes leaving/entering the bottom of the roof structure. 
234 Table 2: Mean Bias Error, Percentage Bias, Root Mean Square Error, Percentage Root 235 Mean Square Error, and Nash-Sutcliffe Efficiency for PROM-modeled heat flux. The 236 shaded cells display the error parameters for the heat flux at the top of the insulation, 237 underneath the membrane, while the un-shaded cells represent errors compared to the 238 bottom heat flux plate measurements.

\begin{tabular}{llllll}
\hline & $\begin{array}{l}\text { MBE } \\
\left(\mathbf{W ~ m}^{-2}\right)\end{array}$ & $\begin{array}{l}\text { PBIAS } \\
(\%)\end{array}$ & $\begin{array}{l}\text { RMSE } \\
\left(\mathbf{W ~ m}^{-\mathbf{2}}\right)\end{array}$ & $\begin{array}{l}\text { PRMSE } \\
(\%)\end{array}$ & NSE \\
\hline ADMw-R8.4 & 3.52 & 48 & 6.65 & 71.3 & 0.49 \\
& 0.08 & 6.7 & 0.42 & 30.73 & 0.87 \\
\hline EGRb-R6.3 & 1.92 & 11 & 17.92 & 74.01 & 0.38 \\
& -0.014 & 0.4 & 1.53 & 36.6 & 0.86 \\
\hline LSBb-R4.2 & -0.74 & 3.8 & 13.67 & 53.78 & 0.71 \\
& -0.33 & 6.18 & 1.42 & 23.15 & 0.94 \\
\hline LSBw-R4.2 & 0.59 & 4.7 & 7.88 & 51.95 & 0.72 \\
& 0.059 & 2.07 & 0.86 & 25.21 & 0.87 \\
\hline THYb-R3.7 & 1.97 & 15.82 & 11.96 & 67.55 & 0.54 \\
& -1.18 & 21.5 & 2.38 & 37.17 & 0.86 \\
\hline
\end{tabular}

240 The average PBIAS for the top heat flux, underneath the membrane is $17 \%$, compared to

$2417 \%$ for the bottom heat flux. The corresponding NSE index, which indicates the strength

242 of the model to predict observed values, improves from a modest 0.56 for the modeled

243 top to 0.88 for bottom heat fluxes. As explained above, the higher error values at the top

244 of the roof, underneath the membrane, are potentially due to the low sampling rate of the

245 forcing data. However, the errors observed at the bottom of the roof are on the order of

246 the accuracy of the measurements of the heat flux plates. In addition, bias errors, which

247 are much lower than RMS errors here, are more representative of the model's

248 performance when time-averaged or time-integrated heat fluxes are considered, which

249 will be the case for this study where we focus on yearly heating and cooling loads. 
250 In addition to heat flux validations at the top and the bottom of the roof layer, figure 4

251 compares the rxternal roof surface temperature simulated by the model to its observed

252 values. Similar to heat fluxes, the model performs well in simulating the diurnal variation

253 of roof temperatures. In particular, the model captures the peak temperature values during

254 the midday period and the nightly lows well. The anomalies are a result of minor

255 differences in accurately defining the thermal properties of the membrane and shading 256 caused by buildings adjacent to the roof. The MBE, RSMSE and NSE values for ENGb

257 and LSBw are [0.62 K, 3.26 K and 0.96] and [3.73 K, 7.30 K and 0.83]. respectively.

258 These comparisons demonstrate that PROM is a robust and reliable tool for modeling 259 heat fluxes through the roofs for the purposes of this study.

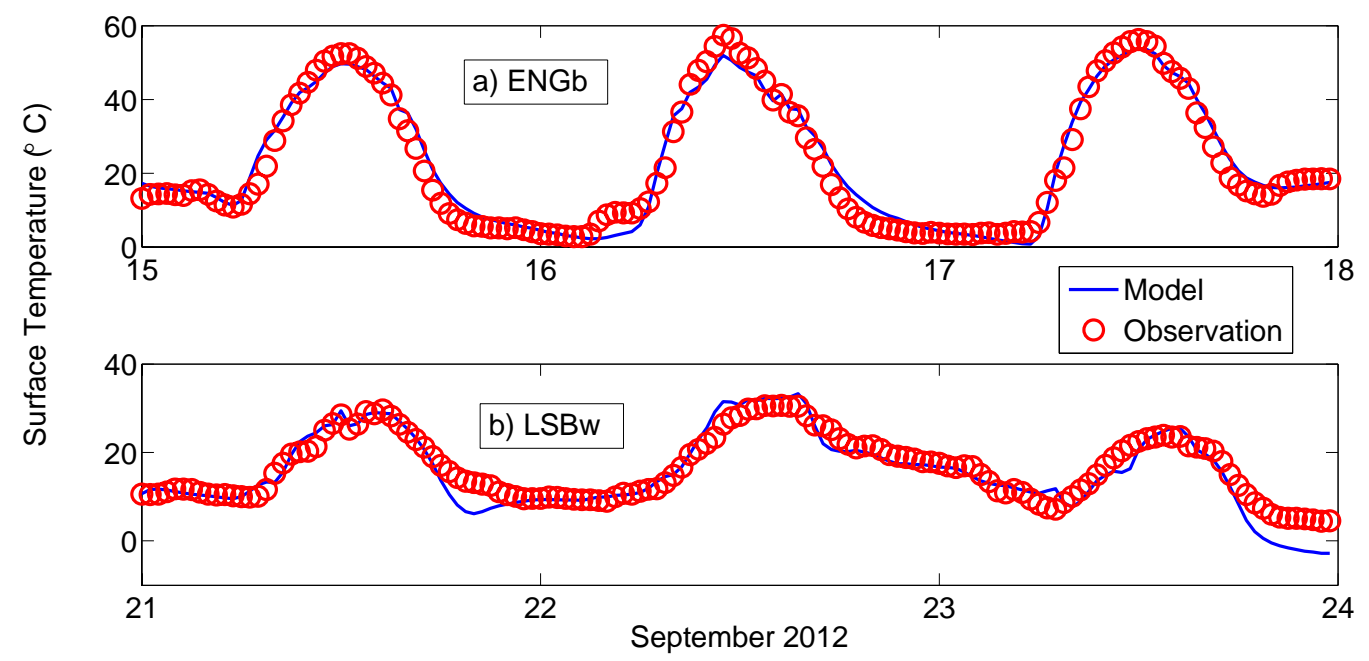

262 Figure 4: Comparing observed surface temperature measurements made at ENGb (a) and 263 LSBw (b) to PUCM simulations.

\section{Model setup}

266 The primary objective of this study is to provide guidance on the optimal combination of

267 roof insulation thickness and roof surface albedo in terms of costs incurred; minimizing 
268 the cost is also expected to yield significant energy savings but this has to be confirmed

269 through the analyses. To that end, a modular conventional roof structure consisting of

270 three layers, an EPDM membrane at the top, PolyIso foam insulation in the middle, and a

271 concrete deck at the bottom, was simulated. Based on the calibrated values in table 1,

272 EPDM, PolyIso and the concrete deck were assigned thermal conductivities of $0.3,0.023$

273 and $1.16 \mathrm{~W} \mathrm{~K}^{-1} \mathrm{~m}^{-1}$, respectively, while their volumetric heat capacities were set to 1.74 ,

2740.07 and $0.4 \mathrm{MJ} \mathrm{K}^{-1} \mathrm{~m}^{-3}$, respectively. For different simulations, the albedo of the

275 rooftops was varied from 0.05 to 0.75 , in steps of 0.15 , and the insulation foam thickness

276 was varied from 0 to $23.876 \mathrm{~cm},(0.0025,3.5763,5.6083,9.2659,14.1427,19.0195$,

277 23.876). In terms of $\mathrm{R}$-value, this is equivalent to varying the roof insulation from R0.17

278 to R10.5 (the US equivalent is from R1 to R60 (R1, R10, R15, R24, R36, R48 and R60)).

279 The thermal properties of all the materials were fixed and remained unchanged between

280 simulations. Other model parameters are listed in table 3.

281

282 Table 3: Physical and aerodynamic properties used in PROM

\begin{tabular}{|l|l|}
\hline \multicolumn{1}{|c|}{ Properties } & \multicolumn{1}{c|}{ Values } \\
\hline Thermal roughness length for roof surface & $0.001 \mathrm{~m}$ \\
\hline Momentum roughness length for roof surface & $0.01 \mathrm{~m}$ \\
\hline Roof surface albedo & {$[0.050 .150 .300 .450 .600 .75]$} \\
\hline Roof surface emissivity & {$[0.92]$} \\
\hline $\begin{array}{l}\text { Roof volumetric heat capacity } \\
\text { [EPDM, PolyIso, Deck] }\end{array}$ & {$[1.74,0.07,0.42] \times 10^{6} \mathrm{JK}^{-1} \mathrm{~m}^{-3}$} \\
\hline Roof thermal conductivity [EPDM, PolyIso, Deck] & {$[0.3,0.023,1.16] \mathrm{WK}^{-1} \mathrm{~m}^{-1}$} \\
\hline Roof thickness [EPDM, Deck] & {$[0.0028,0.254] \mathrm{m}^{-1}$} \\
\hline PolyIso Variable Thickness & {$[0.0025,3.5763,5.6083$,} \\
& $9.2659,14.1427,19.0195$, \\
& $23.876] \mathrm{cm}$ \\
\hline Internal constant building temperature & $23^{\circ} \mathrm{C}$ \\
\hline
\end{tabular}


284 Input meteorological data for the model were obtained from an eddy covariance flux 285 tower located on the campus of Princeton University, Princeton, NJ, which is about $4 \mathrm{~km}$

286 from the experimental roofs. The incoming longwave and shortwave radiation were

287 observed using a HuskeFlux 4-component radiometer, NR01 (accuracy: +/- 10\% for

288 daily totals). A Campbell Scientific CSAT3 sonic anemometer was used to measure the

289 wind speed (accuracy (offset error): less than $+/-0.08 \mathrm{~m} \mathrm{~s}^{-1}$ for the horizontal wind

290 components and less than $+/-0.04 \mathrm{~m} \mathrm{~s}^{-1}$ for the vertical wind component) and a Vaisala

291 HMP45C was used to observe air temperature and specific humidity (accuracy for RH:

$292+/-3 \%$ and for temperature $+/-0.5^{\circ} \mathrm{C}$ ). A LICOR 7500 (accuracy: $+/-1.5 \%$ ) was used to

293 measure atmospheric pressure. The simulations were forced using data gathered between

294 May $1^{\text {st }}, 2010$ and $30^{\text {th }}$ April 2011. The averaged monthly variation in temperature for the

295 12-month period is shown in figure 5. While May through September represented the

296 warmer period or the cooling period, November through March was the heating period

297 during the colder months. The average temperatures during the summer months (June-

298 August) were around $30^{\circ} \mathrm{C}$, daily peaks close to $38^{\circ} \mathrm{C}$ were not uncommon. January was

299 the coldest month with average daily temperatures close to $0^{\circ} \mathrm{C}$. Overall, the cooling and 300 heating degree days for this one year period were 1397 and 5086, respectively.

\section{One year run}

303 Multiple runs over the same one-year period were completed with the data gathered from

304 Princeton and for the various combinations of albedo and roof thicknesses discussed

305 above. Figure 6 shows the variation of the heat transfer through the roof for various

306 albedo values for warmer (May-September, heat gain) and colder (October-March, heat 
307 loss) months; April is omitted since it is a mild month with relatively low gains or losses.

308 The $\mathrm{x}$-axis represents the insulation thickness in $\mathrm{cm}$ (the equivalent $\mathrm{R}$-values are shown

309 just inside the axis box), and the y-axis represents the average heat lost/gained per unit

310 area per day. In the figure, the heat lost through the roof structures is taken as negative

311 and shown on the negative axis, while the heat gained during the warmer months is

312 positive. The average heat entering/leaving the roof structure per unit area per day $J_{0}$

$313\left(\mathrm{~J} \mathrm{~m}^{-2} \mathrm{day}^{-1}\right)$ was calculated following:

$$
J_{0}=\frac{1}{N_{d}} \int_{t_{1}}^{t_{2}} Q d t,
$$

315 where, $Q$ indicates the heat flux between the roof deck and the interior of the building

$316\left(\mathrm{~W} \mathrm{~m}^{-2}\right) ; N_{d}$ represents the total number of days; and $t_{1}$ and $t_{2}$ are the start and end time

317 periods (s).

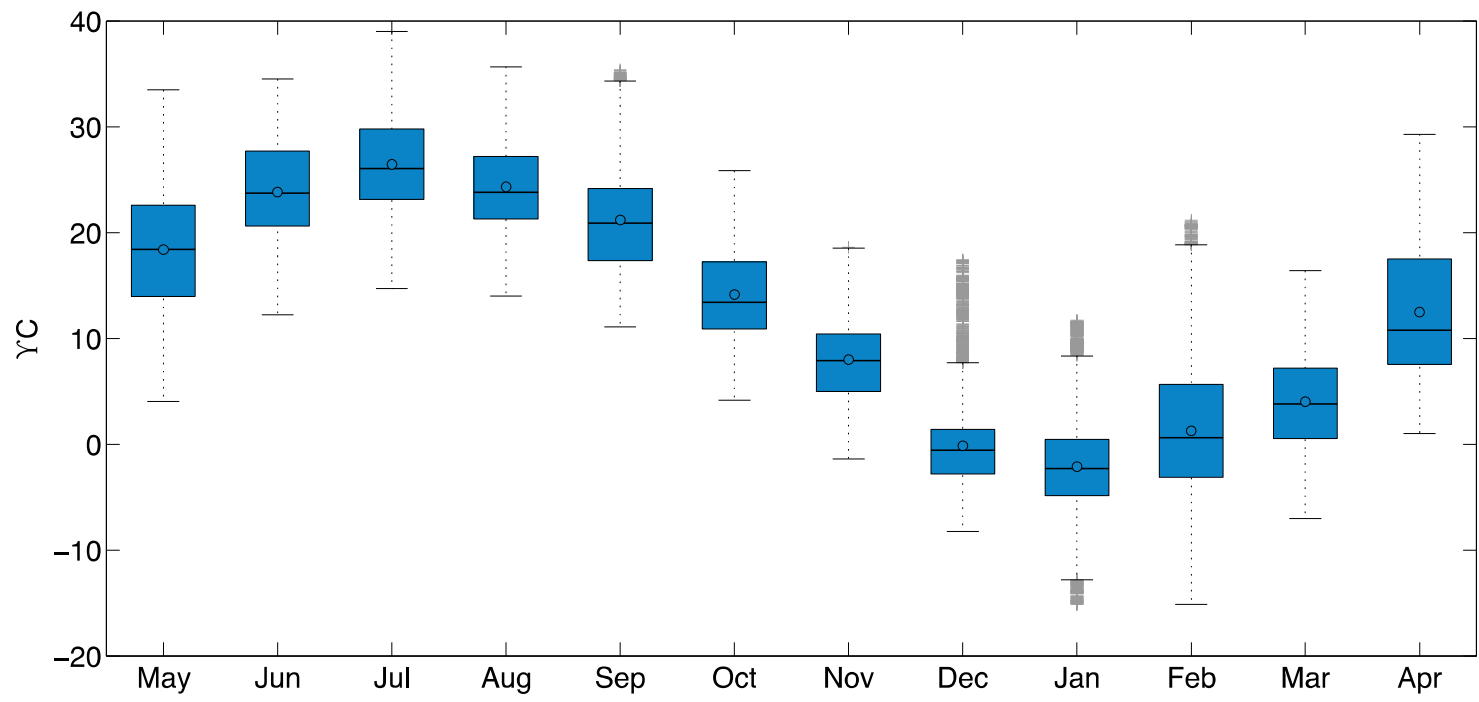

319 Figure 5: Boxplot showing monthly variation in ambient temperatures for the one year run, recorded at Princeton, NJ. The top edge of the box represents the $75^{\text {th }}$ percentile and the bottom edge represents the $25^{\text {th }}$ percentile. The top and bottom whiskers represent the $95^{\text {th }}$ and the $5^{\text {th }}$ percentile. The horizontal black line shows the median and the circle

323 indicates the mean. The plus symbols represent data points that are removed from the

324 mean by more than \pm one-and-a-half times the interquartile range. 
331 Analyzing the summer months, it is clear that for very low insulation thickness, the

332 differences between various albedo values are quite significant. When insulation

333 thickness is less than $4 \mathrm{~cm}$, a roof with an $\alpha=0.05$ gains $718 \mathrm{KJ} \mathrm{m}^{-2}$ day $^{-1}$ compared to a

334 highly reflective roof $(\alpha=0.75)$, which only gains $212 \mathrm{KJ} \mathrm{m}^{-2} \mathrm{day}^{-1}$. While the heat

335 gained is reduced as insulation thickness increases, even for a moderately insulated R6.3

336 roof, the heat gains from the lowest albedo roof are nearly four times higher than from

337 the highest albedo roof: the highly reflective $\mathrm{R} 6.3$ roof gains $54 \mathrm{KJ} \mathrm{m}^{-2}$ day $^{-1}$ compared

338 to a black $(\alpha=0.05)$ roof that admits $190 \mathrm{KJ} \mathrm{m}^{-2}$ day $^{-1}$. When the insulation thickness

339 exceeds $18 \mathrm{~cm}$, the heat gained for all albedo values remains almost constant, indicating

340 that additional insulation is not needed. The family of curves shows that, for warmer

341 months, albedo plays a dominant role in reducing the energy gained through the roofs. In

342 fact, increasing the albedo of a very low insulation roof ( $<\mathrm{R} 10)$ from $\alpha=0.05$ to $\alpha=0.75$ 
343 is roughly equivalent to adding $14 \mathrm{~cm}$ of insulation thickness (see more on this concept of

344 expressing the increase in albedo as an equivalent increase in R-value in Gaffin et al. [4]).

345 In stark contrast, during the colder months, the differences in albedo values do not affect

346 the heat loss in a significant manner. For a roof with less than $4 \mathrm{~cm}$ of insulation (lesser

347 than R10), the difference in heat lost between $\alpha=0.05$ and $\alpha=0.75$ is roughly $125 \mathrm{KJ}$

$348 \mathrm{~m}^{-2} \mathrm{day}^{-1}$, and for a roof with insulation thickness higher than $24 \mathrm{~cm}$ the difference is

349 reduced to $50 \mathrm{KJ} \mathrm{m}^{-2}$ day $^{-1}$. However, insulation thickness plays a dominant role in

350 controlling the heat loss through the roof structures. A roof with $\alpha=0.30$ loses nearly

$351600 \mathrm{KJ} \mathrm{m}^{-2} \mathrm{day}^{-1}$ at $\mathrm{R} 10$ compared to $175 \mathrm{KJ} \mathrm{m}^{-2}$ day $^{-1}$ at R6.3. Similar to warmer

352 months, this difference is significantly reduced for insulation thickness greater than 18

$353 \mathrm{~cm}$ (R8.4). As we also point out in the associated experimental study [2], this discrepancy

354 between summer time benefits and winter time penalties of cool roofs, despite the fact

355 that the northeastern US has about 5 times more heating degree days than cooling degree

356 days, is related to the negligible impact of albedo during peak heating periods (which

357 occur during nighttime and in the winter when the insolation periods are short), as

358 opposed to its prominent role during peak cooling periods (occurring in the afternoon and

359 in the summer when the insolation periods are long).

360 The model results suggest that for newer constructions, a high albedo $(\alpha>0.7$, although

361 this value might be difficult to maintain for roofs as they age in practice) - R8.4 roof is a

362 practical solution for significantly reducing energy losses/gains during winter and

363 summer months at the NYC Metropolitan region. Beyond an R8.4 roof insulation, the

364 reductions in energy consumption become incremental. Another point to underline is that

365 since it is difficult to maintain high reflectivity over an extended period of time, a thick 
366 insulation layer would reduce the need to constantly maintain high membrane reflectivity.

367 Rain, dust and air pollution are known to reduce the solar reflectance of white roofs [29];

368 the decline in solar reflectance, particularly in the first year of operation, could be

369 considerable. Bretz et al. [28] found that some white roofs lost nearly $70 \%$ of their

370 reflectivity within a year, resulting in an estimated $20 \%$ reduction in energy savings for

371 succeeding years compared to the savings in the first year. The staining causing albedo

372 reduction, while not permanent, would require considerable effort to remove and regain

373 the original reflectivity. Bretz et al. [28] tested 40 samples of weathered and unweathered

374 roofs obtained from various regions in US and Canada and suggested periodic power

375 washing to maintain the membrane reflectivity. At the PPPL site, over the ADMw-R8.4

376 roof, an area of $1 \mathrm{~m} \times 1 \mathrm{~m}$ was cleaned thoroughly and the subsequent change in albedo

377 was observed. Figure 7 depicts the daily variation in the albedo measured during peak

378 solar radiation from May 1, 2012 to October 1, 2012. In the five-month period, the roof

379 albedo dropped dramatically from $\approx 0.65$, post cleaning, to $\approx 0.35$. In fact, during a 15 -

380 day period, beginning June 2012 , the albedo suddenly dropped by more than $25 \%$ before

381 stabilizing at around 0.35 after the beginning of August 2012. 


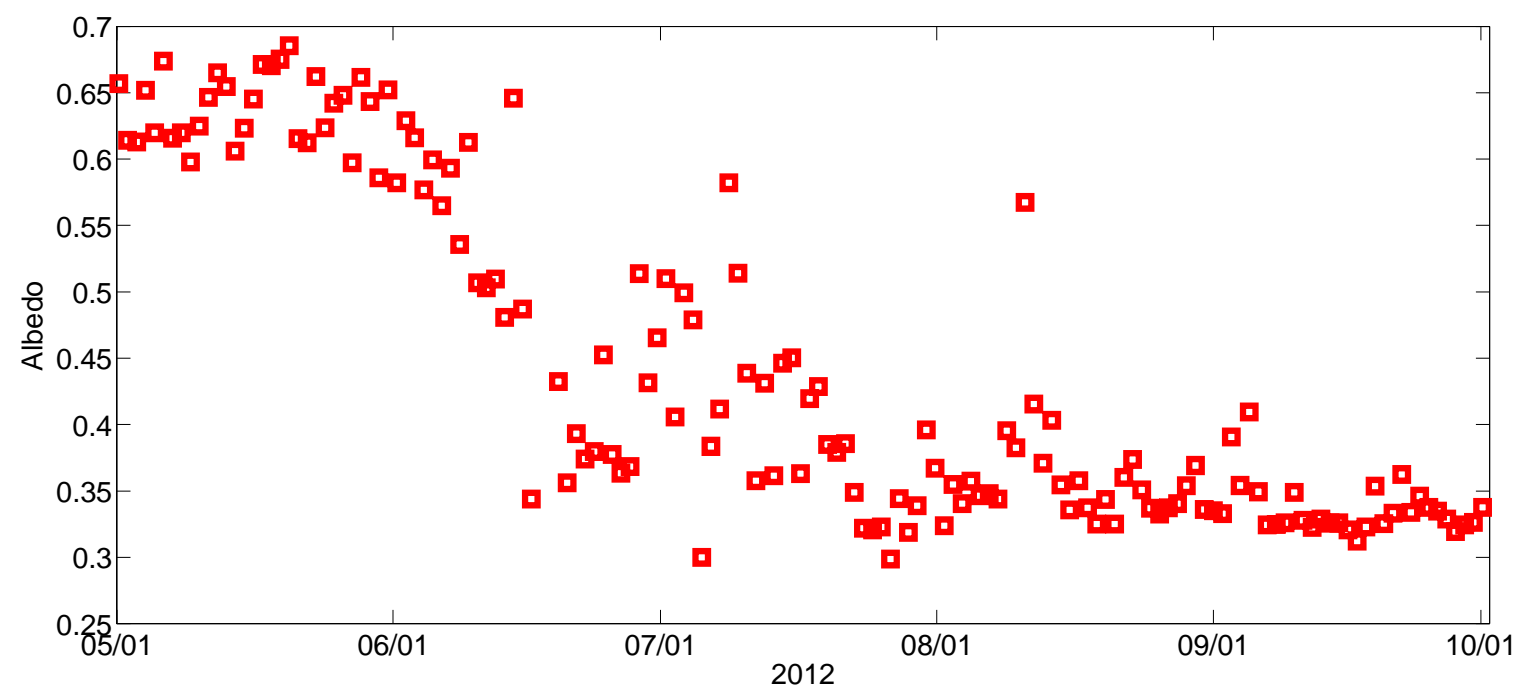

382

383

384

385

Figure 7: Variation in peak time albedo over the reflective ADMw-R8.4 roof at the PPPL test site in Princeton, NJ, after cleaning.

386 White roofs, on the other hand could be advantageously used to moderate the urban

387 microclimate. Urban areas, in general experience higher temperatures compared to the

388 surrounding rural environment though what is now a very well documented

389 anthropogenic climate modification known as the Urban Heat Island (UHI) effect [30],

390 [31]. Apart from increased anthropogenic heat releases, the thermal and radiative

391 properties of the built environment sustain this higher energy state [32]. This

392 phenomenon has a direct impact on human health [33], as it abets and augments the

393 impact of heat waves in urban areas and also increases cooling loads on air conditioning

394 systems [34] by raising the ambient air temperature. White/Cool roofs can be effectively

395 used to reduce the impact of UHI by reflecting most of the incoming shortwave radiation

396 back in to the atmosphere. This will remain a significant advantage of such roofs even if

397 higher insulation reduces the direct impact of albedo on heat transfer in/out of the 398 building. 
399 To illustrate this microclimatic influence of white roofs, figure 8 shows the influence of

400 albedo and roof insulation on the simulated convective sensible heat flux from the roof to

401 the atmosphere for the warmer months. Unlike the ground/roof flux seen in figure 6,

402 sensible heat flux is entirely dependent on albedo. Insulation thickness does not play a

403 role in determining the magnitude of sensible heat and the figure clearly shows that as

404 insulation thickness increases, the sensible heat remains almost constant for all albedos.

405 Importantly, as albedo values increase, sensible heat flux falls down rapidly. The

406 magnitude of sensible heat flux released to the atmosphere decreases to nearly $2 \mathrm{MJ} \mathrm{m}^{-2}$

$407 \mathrm{day}^{-1}$ from $12 \mathrm{MJ} \mathrm{m}^{-2} \mathrm{day}^{-1}$ as the albedo values decrease from 0.75 to 0.05 . Even a more

408 modest increase in albedo, from 0.05 to 0.45 reduces the sensible heat values by half.

409 Sensible heat flux is directly responsible for maintaining high near-surface air

410 temperatures in urban areas relative to the surrounding rural areas, thus producing the

411 urban heat island effect. As such, variations in this flux, if cool roofs are widely adopted

412 in a given city, will result in indirect improvement in building energy consumption by

413 reducing the summertime outdoor temperatures [35]. These indirect impacts are not

414 quantified in this study since they depend on the fraction of cool roofs adopted at the city-

415 scale

416 Recent work has highlighted the costs and benefits of using white roofs compared to 417 black and green roofs [36]. Akbari et al. [8] found that nationwide implementation of

418 high albedo roofs can lead to $\$ 1$ billon in annual energy savings and decrease the urban

419 air temperature by at least $0.5^{\circ} \mathrm{C}$. This has lead to campaigns such as the Global Cool

420 Cities alliance [37] and the NYC Cool Roof initiative [38], that are dedicated to

421 increasing the solar reflectance of urban roofs. 


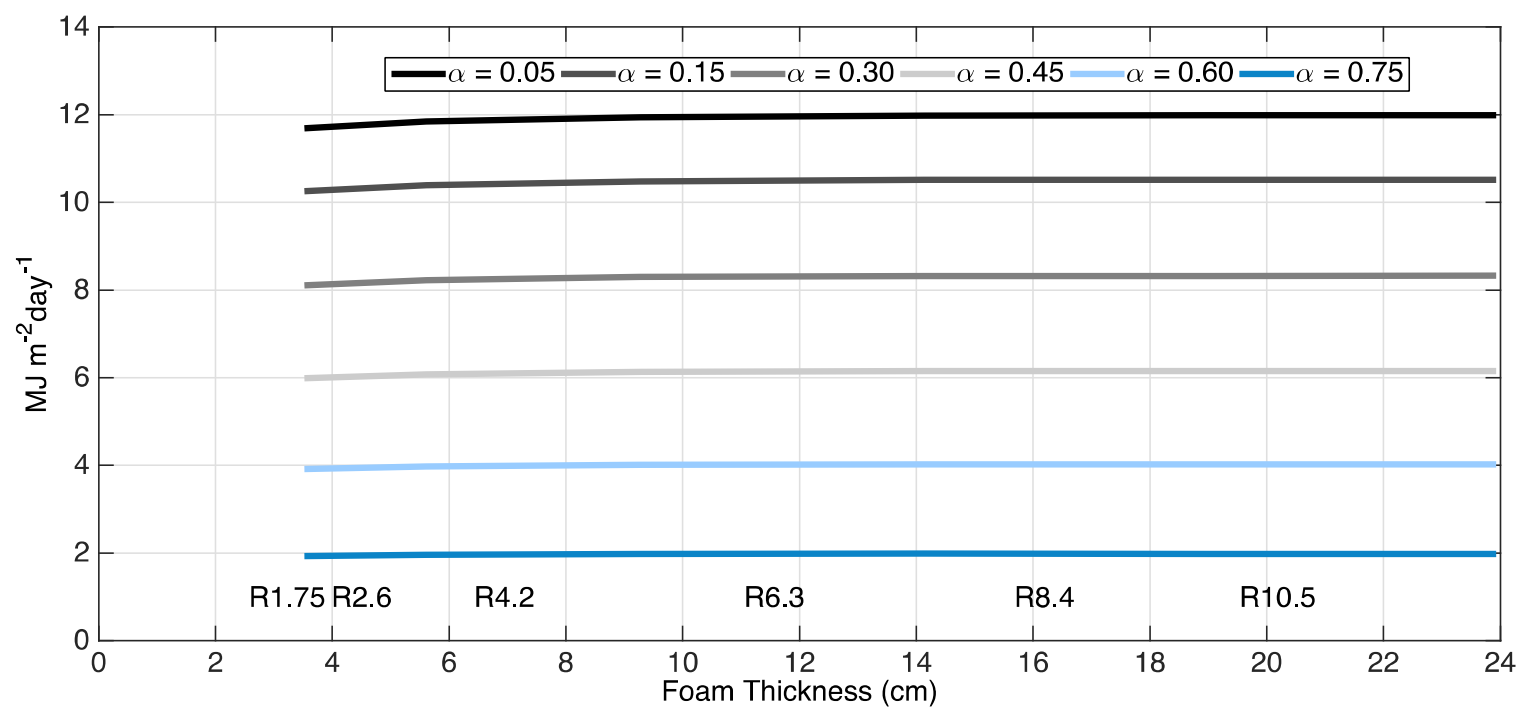

423 Figure 8: Modeled sensible heat flux released during warmer months (May to 424 September) as a function of insulation thickness from the one-year simulations using 425 PROM. The curves represent different albedos $\alpha$.

427 While a high albedo $(\alpha=0.7)$ and R8.4 might be the perfect combination for newer roof 428 structures, for older roof structures (based on bitumen or asphalt shingles) that are 429 commonly found in the northeastern United States, a white paint coat during summer 430 months would be highly beneficial. Roofs constructed around the mid-twentieth century 431 have very low insulation in general; they are mostly coated with tar and covered by a 432 layer of gravel. These remain the most commonly-found roof structures in the 433 northeastern United States, which in general has an older housing stock [39]. Apart from

434 their lack of proper insulation layer, the gravel and tar increase the radiative absorptivity 435 of the roof structure. This combination makes them highly ineffective in preventing 436 building heat gains, as well as excessive heating of the lower atmosphere during warmer 437 months. Wide adoption of white roofs will thus result in reductions in urban air 438 temperatures [35] that will feed back to further reduce building energy consumption. 


\section{Cost Optimization Analysis}

440 The costs incurred for various roof combinations were calculated along with the energy

441 lost/gained. To compute the costs, a chilled water cooler and a natural gas furnace were

442 assumed to cool and heat the space during the summer and winter periods. These two

443 modes are the most widely adopted means of air conditioning in US commercial

444 buildings [40]. The heat entering and leaving the building through the roof was obtained

445 from the PROM's yearlong simulation outputs. For the chilled water system, a COP

446 (coefficient of performance) of 3 was assumed. COP of a heat pump is defined as the

447 ratio of heat supplied or removed to work done. Hence, a COP of 3 indicates that 3 units

448 of heat are removed for every 1 unit of energy consumed. For winter heating, a

449 conservative $60 \%$ efficiency was assumed, which equates to burning $29.307 \mathrm{kWh}$ (1

450 therm) of natural gas to produce $63 \mathrm{MJ}$ of energy.

451 The costs of electricity and natural gas were assumed to be $\$ 0.201$ per $\mathrm{kWh}$ and $\$ 1.124$

452 per $29.307 \mathrm{kWh}$ (1 therm), respectively [41]. The values indicated above represent the

453 average 2012 prices for electricity and natural gas in the New York Metropolitan region

454 (Princeton, NJ is located on the fringes of NYC Metropolitan area).

455 Figure 9 shows the savings in energy cost for a moderately reflective ( 0.45 albedo) roof

456 as a function of PolyIso foam insulation thickness (this does not yet account for costs). A

457 conservative albedo value of 0.45 was picked based on our experimental evidence that

458 showed it was highly unlikely to maintain much higher reflectivity of white roofs for

459 extended periods. The relationship shown in figure 9 was computed by adding the

460 summer and winter savings for each step increase in insulation thickness. This way, the

461 winter penalty for high albedo roofs was subtracted from the summer savings. The net 
462 sum was calculated for multiple insulation thicknesses and a power law fit was then

463 introduced to capture the trend (this fit will be used in the remainder of this section for

464 the studied roof, but is not intended as a generalizable result for other roofs). Figure 9

465 shows that increasing the insulation thickness from none (only concrete deck) to $5.08 \mathrm{~cm}$

466 (2 in) will result in energy savings close to $\$ 12 \mathrm{~m}^{-2}$, and increasing from $5.08 \mathrm{~cm}$ to 10.16

$467 \mathrm{~cm}(4 \mathrm{in})$ would further lower the cost by $\$ 0.83 \mathrm{~m}^{-2}$ over a year.

468

469

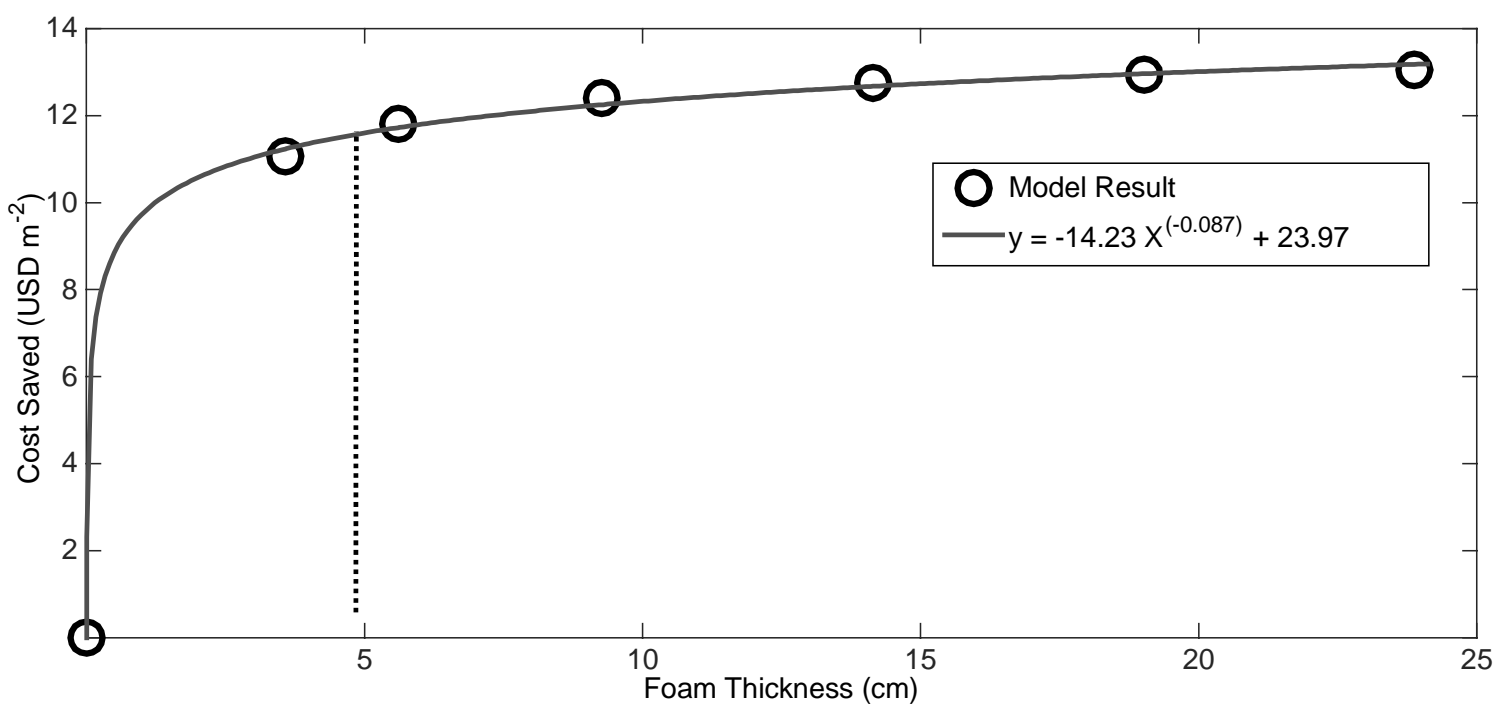

470 Figure 9: Energy costs saved in terms of PolyIso insulation foam thickness (not 471 including costs incurred in insulating the roof). The dotted line indicates the baseline 472 thickness, $4.508 \mathrm{~cm}$ (2 in). The circles indicate the simulated values from the model and 473 the line represents the power law fit. The zero foam thickness simulation corresponds to a 474 bare roof with a concrete deck (0.254 m thickness), as per table 1.

476 The analysis above does not yet account for the costs of adding the insulation. Assuming 477 a baseline thickness of $5.08 \mathrm{~cm}$ (PolyIso roof insulation is readily available in 478 prefabricated $5.08 \mathrm{~cm}$ thick (2 in) slabs, which is commonly used by commercial roof 479 installers) and fixing the price of one PolyIso foam slab to $\$ 7.5 \mathrm{~m}^{-2}$ (this price is based on 480 our inquiry to multiple commercial installers in the Northeastern US), the cost recovery 
481 time for the investment in upgrading the insulation can be calculated using the following 482 equation [36]:

$$
N S_{x y}=\sum_{t=0}^{N} \frac{S_{x y}(1+e)^{t}}{(1+d)^{t}}-\sum_{t=0}^{N} \frac{C_{x y}(1+e)^{t}}{(1+d)^{t}}
$$

484 In equation 7, $S_{x y}$ and $C_{x y}$ represent respectively the total savings (as in figure 9) and costs

485 incurred by adding an additional layer of insulation foam over the baseline of 2 in. $S_{x y}$ is

486 calculated from the power fit relationship computed above. For this analysis, maintenance

487 cost is omitted, as it would remain about constant, irrespective of additional insulation

488 layers. $C_{x y}$ thus only includes material cost, which is just the initial cost at $t=0$. In the

489 equation, $e$ is the annual fuel price escalation rate. The average fuel price escalation rates

490 for natural gas and electricity for the northeastern US are expected to be $-1.0 \%, 0.85 \%$,

$4910.4 \%$ and $0.6 \%$ for the periods 2012-2017, 2017-2022, 2022-2027 and 2027-2032,

492 respectively [42]. The intergenerational real discount rate $d$, which accounts for future

493 costs and benefits is set at 3.0\% [43]. In the equation, $N$ represents the year number and

$494 N S_{x y}$ is the present value of the net savings. A negative $N S_{x y}$ implies net losses and a

495 positive one implies net savings.

496 Based on equation 7, the break even time to recover the material cost for doubling, 497 tripling and quadrupling the insulation thickness from the baseline case, i.e. when $498 N S_{x y}=0$, is found to be 13,17 and 19 years respectively. At the end of the life cycle (20 499 years), the net savings for all three cases is $\$ 3.7 \mathrm{~m}^{-2}, \$ 2.5 \mathrm{~m}^{-2}$ and $\$ 0.35 \mathrm{~m}^{-2}$. This 500 indicates that a 4-inch insulation maximizes the savings over a 20-year expected life of

501 the roof. While these numbers are encouraging, many commercial establishments would 502 find the 13-19 year recovery period too high, despite the fact that the average life span of 503 a roof structure is around 20 years. Furthermore, the cost of borrowing money to 
504 undertake such renovations was not fully accounted for since the intergenerational real

505 discount rate $d$ would likely be lower than the borrowing costs of these commercial

506 establishments. However, only direct energy savings are accounted in this analysis since

507 they have immediate and noticeable benefits to the consumer. Adding additional layers of

508 insulation also has a myriad other socio-economic benefits: health benefits due to lower

509 NOx and SOx emissions from power plants, reduced $\mathrm{CO}_{2}$ emission and the associated

510 impacts related to advancing climate change mitigation strategies, etc. Hence, since our

511 computations indicate that there is a net socio-economic benefit associated with such roof

512 upgrades, tax incentives or rebate plans could be developed to reduce the cost recovery

513 period to 10 years, thus encouraging the businesses to undertake the upgrade and

514 allowing for the various socio-economic benefits to be actualized.

515

5166 Conclusion

517

518 The analysis detailed in this paper focused on identifying the optimal combination of roof

519 insulation and roof reflectivity. The yearlong simulations using the Princeton ROof

520 Model (PROM), forced by meteorological data for the NYC Metropolitan region, show

521 that for newer constructions, an R8.4 roof with a highly reflective membrane $(\alpha>0.7)$

522 would be ideal in reducing the heat gained/lost, when the warmer and colder months are

523 aggregated. Since maintaining roof reflectivity remains a challenge, the highly insulated

524 R8.4 roof would considerably decrease the energy exchanges between the building roof

525 and the surrounding environment and would eliminate the need to frequently clean the

526 roofs to maintain high reflectivity. However, even with higher insulations, cool roofs are

527 still advantageous, particularly for mitigating the urban heat island effect. Higher albedo 
528 roofs resulted in significant reductions in the sensible heat transferred from the roofs to

529 the atmosphere in our simulations.

530 The results illustrate that for older buildings that suffer from lack of proper insulation,

531 increasing the albedo would help cut energy costs during the warmer months. This study

532 also found that the energy and cost benefits of using white roofs clearly outweigh the

533 wintertime penalty. The physical reason for this discrepancy between summer time

534 benefits and winter time penalties of cool roofs, despite the fact that the northeastern US

535 has about 5 times more heating degree days than cooling degree days, is related to the

536 negligible impact of albedo during peak heating periods (which occur during nighttime

537 and in the winter when the insolation periods are short), as opposed to its prominent role

538 during peak cooling periods (occurring in the afternoon and in the summer when the

539 insolation periods are long). Despite using meteorological data to force the model from

540 the Northeastern United States, our results are pertinent to many other densely populated

541 areas with comparable climates (e.g. northern Europe, China, Japan) where, despite a

542 much higher number of heating versus cooling degree-days, our findings indicate that

543 white roofs would be overall advantageous due to the asymmetry in the role and impact

544 of albedo between the summer and winter time.

545 The model runs have also highlighted the importance of insulation thickness in reducing

546 building energy consumption. Roughly, doubling the insulation thickness halves the heat

547 lost during the colder months, which is the result to be expected from steady state heat

548 transfer through the roof. Our analyses also indicate that additional layers of insulation

549 foam help in offsetting the loss of reflectivity suffered by white roofs. However, the cost

550 optimization analysis showed that the time to recover the additional cost incurred by 
551 adding extra layers of insulation is moderately high by current pricing standards.

552 Commercial roofs have a lifespan of around 20 years, private enterprises might be

553 dissuaded by the relatively high recovery periods of 13,17 and 19 years for doubling,

554 tripling and quadrupling the thickness from the baseline case $(5.08 \mathrm{~cm})$. These results

555 apply only to the Northeastern United States, but the methodology we describe and use to

556 generate them can be easily applied to other regions to obtain the corresponding cost

557 recovery periods.

558 In order to encourage commercial establishments to move towards green buildings and

559 energy sustainability, policy makers can incentivize adding insulation layers either by

560 subsidizing the cost of additional insulation layers, or through tax benefits. Currently

561 many city and state administrations in the U.S. subsidize the cost of green roofs or offer

562 tax credits. For example, in New York City and Philadelphia, consumers can receive up

563 to $\$ 100,000$ in tax credits for converting more than half of their conventional roof to

564 green roof $[44,45]$. The Portland city administration offers zoning incentives for green

565 roof installations [46]. In Arizona, green energy standards are mandatory for state and

566 state-funded buildings [47]. In a similar fashion, policy makers in other cities and states

567 should strongly consider incentivizing the addition of layers of roof insulation, as well as

568 measures that increase the albedo

569 Overall, this study has unraveled the interacting roles played by roof reflectivity and

570 insulation thickness in modulating the heat gained/lost through heterogeneous roof

571 structures. Our results clearly demonstrate that high albedo roofs with thicker insulation

572 can cost-effectively reduce energy consumption for heating and cooling in buildings.

573 Furthermore, we reiterate that cool roofs will help moderate extreme heat in cities, as 
574 well as provide urban planners and policy makers with an affordable but effective mode

575 to advance towards urban energy sustainability.

576

577

578

579 This work was supported by the US Department of Energy through Pennsylvania State

\section{Acknowledgements:}

580 University's Energy Efficiency Building Hub under grant No. DE-EE0004261 and by the

581 Helen Shipley Hunt Fund through Princeton University. The authors also extend their

582 gratitude to the staff members at PPPL for their invaluable help in setting up the

583 experiment.

584

585

586

587

588

589

590

591

592

593

594

595

596

597

598

599

600

601

602

603

604

605

606

607

608

609

610

611

612

\section{References:}

[1] U. D. O. Energy, “2011 Building energy Data Book,” 01-Mar-2012. [Online].Available:http://buildingsdatabook.eren.doe.gov/docs/DataBooks/2 011_BEDB.pdf.

[2] P. Ramamurthy, T. Sun, K. Rule, and E. Bou-Zeid, "The Joint Influence of Albedo and Insulation on Roof Performance: An Observational Study," Energy and Buildings, vol. 93, pp. 249-258, 2015.

[3] Z. Wang, E. Bou-Zeid, and J. A. Smith, "A coupled energy transport and hydrological model for urban canopies evaluated using a wireless sensor network," Quarterly Journal of the Royal Meteorological Society, vol. 139, no. 675 , pp. 1643-1657, 2013.

[4] S. R. Gaffin, M. Imhoff, C. Rosenzweig, R. Khanbilvardi, A. Pasqualini, A. Y. Y. Kong, D. Grillo, A. Freed, D. Hillel, and E. Hartung, "Bright is the new black-multi-year performance of high-albedo roofs in an urban climate," Environ. Res. Lett., vol. 7, no. 1, p. 014029, Mar. 2012.

[5] M. Santamouris, "Cooling the cities-a review of reflective and green roof mitigation technologies to fight heat island and improve comfort in urban environments," Solar Energy, vol. 103, pp. 682-703, 2014.

[6] R. Levinson and H. Akbari, "Potential benefits of cool roofs on commercial buildings: conserving energy, saving money, and reducing emission of greenhouse gases and air pollutants," Energy Efficiency, vol. 3, no. 1, pp. 53-109, Mar. 2009. 
[7] E. P. D. Barrio, "Analysis of the green roofs cooling potential in buildings," Energy and Buildings, vol. 27, no. 2, pp. 179-193, Apr. 1998.

H. Akbari, S. Konopacki, and M. Pomerantz, "Cooling energy savings potential of reflective roofs for residential and commercial buildings in the United States," Energy, vol. 24, no. 5, pp. 391-407, May 1999.

N. H. Wong, D. K. W. Cheong, H. Yan, J. Soh, C. L. Ong, and A. Sia, "The effects of rooftop garden on energy consumption of a commercial building in Singapore," Energy and Buildings, vol. 35, no. 4, pp. 353-364, Apr. 2003.

D. J. Sailor, "A green roof model for building energy simulation programs," Energy and Buildings, vol. 40, no. 8, pp. 1466-1478, Apr. 2008.

D. B. Crawley, J. W. Hand, M. Kummert, and B. T. Griffith, "Contrasting the capabilities of building energy performance simulation programs," Part Special: Building Performance Simulation, vol. 43, no. 4, pp. 661-673, 2008.

[13] D. Zhu, T. Hong, D. Yang, and C. Wang, "Comparison of Building Energy Modeling Programs: Building Loads ," U. S. Department of Energy, DEAC02-05CH11231, Apr. 2012.

[14] F. Salamanca, A. Martilli, and C. Yagüe, "A numerical study of the Urban Heat Island over Madrid during the DESIREX (2008) campaign with WRF and an evaluation of simple mitigation strategies," International Journal of Climatology, vol. 32, no. 15, pp. 2372-2386, 2012.

[15] P. Ramamurthy and E. B. Zeid, "Contribution of impervious surfaces to urban evaporation," Water Resources Research, vol. 50, pp. 2889-2902, 2014.

[16] J. Van der Veken, D. Saelens, G. Verbeeck, and H. Hens, "Comparison of steady-state and dynamic building energy simulation programs," presented at the ASHRAE, Atlanta, 2004.

[17] G. D. Raithby, "Evaluation of Discretization Errors in Finite-Volume Radiant Heat Transfer Predictions," Numerical Heat Transfer, Part B: Fundamentals, vol. 36, no. 3, pp. 241-264, 1999. 
[18] D. Wortman, B. O'Doherty, and R. Judkoff, "The Implementation of an Analytical Verification Technique on Three Building Energy Analysis Codes," U.S. Department of Energy, SERI/TP-721-1008, 1981.

T. Sun, E. Bou-Zeid, Z. Wang, E. Zerba, and G. Ni, "Hydrometeorological determinants of green roof performance via a vertically-resolved model for heat and water transport," Building and Environment, vol. 60, pp. 211-224, 2013.

\section{[22] Z. Wang, E. Bou-Zeid, and J. A. Smith, "A spatially-analytical scheme for surface temperatures and conductive heat fluxes in urban canopy models," Boundary-Layer Meteorology, vol. 138, no. 2, pp. 171-193, 2011. \\ [23] P. Ramamurthy, E. Bou-Zeid, J. A. Smith, Z. Wang, M. L. Baeck, N. Z. Saliendra, J. L. Hom, and C. Welty, "Influence of Sub-Facet Heterogeneity and Material Properties on the Urban Surface Energy Budget," Journal of Applied Meteorology and Climatology, vol. 53, pp. 2114-2129, 2014.}

[24] M. C. Peel, B. L. Finlayson, and T. A. McMahon, "Updated world map of the Köppen-Geiger climate classification," Hydrology and Earth System Sciences Discussions, vol. 4, no. 2, pp. 439-473, 2007.

[25] Sensorscope, "Sensorscope Manual," pp. 1-25, 2010.

[26] D. M. S. Al-Homoud, "Performance characteristics and practical applications of common building thermal insulation materials," Building and Environment, vol. 40, no. 3, pp. 353-366, 2005.

J. E. Christian, G. E. Courville, and R. S. Graves, Insulation Materials: Testing and Applications, 1st ed., vol. 2. ASTM, 1991.

[28] S. E. Bretz and H. Akbari, "Long-term performance of high-albedo roof coatings," Energy and Buildings, vol. 25, no. 2, pp. 159-167, 1997.

[29] P. Berdahl, H. Akbari, and L. S. Rose, "Aging of reflective roofs: soot deposition," Applied optics, vol. 41, pp. 2355-2360, 2002. 
[30] T. R. Oke, "The energetic basis of the urban heat island," Quarterly Journal of the Royal Meteorological Society, vol. 108, no. 455, pp. 1-24, 1982.

[31] T. R. Oke, "The urban energy balance," Progress in Physical Geography, vol. 12 , no. 4, pp. 471-508, 1988.

[32] D. Li and E. Bou-Zeid, "Synergistic interactions between urban heat islands and heat waves: the impact in cities is larger than the sum of its parts," Journal of Applied Meteorology and Climatology, vol. 52, no. 9, pp. 20512064, 2013.

[33] W. D. Solecki, C. Rosenzweig, L. Parshall, G. Pope, M. Clark, J. Cox, and M. Wiencke, "Mitigation of the heat island effect in urban New Jersey," Environmental Hazards, vol. 6, no. 1, pp. 39-49, 2005.

[34] M. Santamouris, N. Papanikolaou, I. Livada, I. Koronakis, C. Georgakis, A. Argiriou, and D. N. Assimakopoulos, "On the impact of urban climate on the energy consumption of buildings," Solar Energy, vol. 70, no. 3, pp. 201-216, 2001.

[35] D. Li, E. Bou-Zeid, and M. Oppenheimer, "The effectiveness of cool and green roofs as urban heat island mitigation strategies," Environ. Res. Lett., vol. 9, no. 5, p. 055002, 2014.

[36] J. Sproul, M. P. Wan, B. H. Mandel, and A. H. Rosenfeld, "Economic comparison of white, green, and black flat roofs in the United States," Energy and Buildings, vol. 71, pp. 20-27, 2014.

"Cooler Cities - Global Cool Cities Alliance," globalcoolcities.org. [Online]. Available: http://www.globalcoolcities.org/?page_id=17.

"NYC ${ }^{\circ} \mathrm{Cool}$ Roofs - About NYC ${ }^{\circ} \mathrm{Cool}$ Roofs," nyc.gov. [Online]. Available: http://www.nyc.gov/html/coolroofs/html/home/home.shtml.

J. L. Bradshaw, E. Bou-Zeid, and R. H. Harris, "Comparing the effectiveness of weatherization treatments for low-income, American, urban housing stocks in different climates," Energy and Buildings, vol. 69, pp. 535-543, 2014.

[40] D. Westphalen and S. Koszalinski, "Energy Consumption Characteristics of Commercial Building HVAC Systems," Arthur D. Little, 30-Oct-1999. [Online].Available:http://apps1.eere.energy.gov/buildings/publications/pdfs/ commercial_initiative/hvac_volume2_final_report.pdf.

[41] U.S. Energy Information Administration. [Online]. Available: http://www.eia.gov/dnav/ng/ng_sum_lsum_a_EPG0_PG1_DMcf_a.htm. 
[42] A. S. Rushing, J. D. Kneifel, and B. C. Lippiatt, "Energy Price Indices and Discount Factors for Life-cycle Cost Analysis, 2012," National Institute of Standards and Technology, NISTIR 85-3273-27, 2012.

"Social Cost of Carbon for Regulatory Impact Analysis -- Under Executive Order 12866 -," United States Government, 12866, 2013.

P. E. Salkin, "Sustainability and land use planning: greening state and local land use plans and regulations to address climate change challenges and preserve resources for future generations," Wm. \& Mary Envtl. L. \& Pol'y Rev., vol. 34, p. 121, 2009. "NYC Green Roof Property
RCNY 105-01, Jan. 2010.

J. Foster, A. Lowe, and S. Winkelman, "The value of green infrastructure for urban climate adaptation," The Center for Clean AIr Policy, 2011.

J. Brewer, "Executive order 2005-05 - Implementing Renewable Energy and Energy Efficiency in New State Buildings," State of Arizona, 2005. 